\title{
RETURN TO PROFESSIONAL ACTIVITY BY PATIENTS TREATED SURGICALLY DUE TO ADVANCED GONARTHROSIS
}

\author{
MAREK DROBNIEWSKI, MAREK SYNDER, MAGDALENA KRASIŃSKA, MARCIN SIBIŃSKI, \\ and ANDRZEJ BOROWSKI \\ Medical University of Lodz, Łódź, Poland \\ Orthopedics and Pediatrics Orthopedics Department
}

\begin{abstract}
Objectives: The goal of this work is to analyze the issue of return to professional activity by working-age patients who have been treated surgically with total knee arthroplasty (TKA) due to gonarthrosis. Material and Methods: Overall, 88 working-age patients were examined, with a total of 91 TKA procedures performed due to advanced gonarthrosis. The average age of the patients was 54.2 years for women and 58.1 years for men. A modified Knee Society Score scale was used to compile the results of the clinical trial. The Kellgren-Lawrence classification was used to assess preoperative radiographs. Postoperative radiographs evaluated the position of the endoprosthesis of both the femoral and tibial components in the anteriorposterior and lateral upright projections. The obtained results were subjected to statistical analysis. Results: In the preoperative assessment, both the clinical and radiological results obtained were unfavorable in all cases. Throughout the observation period of approximately over 3.8 years, a very good result was noted in 65 cases (71.4\%), a good result in 20 cases (22\%), and a satisfactory result in 6 cases. There were no bad results. The average improvement on the Visual Analogue Scale was 6.5 pts. The radiological assessment did not reveal any radiological symptoms of the aseptic loosening of the endoprosthesis, simultaneously concluding that each time the endoprosthesis components were properly seated. Only $53(58.3 \%)$ of the examined patients were professionally active before the surgery. After completing the treatment, $46(50.5 \%)$ of all patients returned to work, in favor of intellectual workers. The average duration of sick leave was 136.2 days, and rehabilitation allowance was granted in 19 cases. Conclusions: Firstly, in working-age patients, TKA is a valuable method for surgical treatment of advanced gonarthrosis of varying etiology. Secondly, most of the patients who worked before the surgery returned to performing work in the position held and on the same full-time equivalent basis. Int J Occup Med Environ Health. 2021;34(5):617-28
\end{abstract}

Key words:

total knee arthroplasty, gonarthrosis, return to work, clinical and radiological outcome, Knee Society Score, Kellgren-Lawrence classification

\section{INTRODUCTION}

Degenerative changes of the knee joint are amongst the most frequent reasons why patients visit orthopedic clinics. These changes result in serious consequences for patients, including severe pain, a limited range of motion and difficulty moving. This is the case even among young people; however, the likelihood of degenerative changes definitely increases in patients aged $>45$ years, especially in obese female patients. Total knee arthroplasty (TKA) is currently the method of choice for surgical treatment of advanced forms of knee joint arthrosis (gonarthrosis) of varying etiology. National registers of endoprosthetics indicate that the number of such procedures increases year by year, and it is associated with the observed process of global aging. The development of knee arthroplasty and the results obtained during long-term observations allow

Received: September 7, 2020. Accepted: January 13, 2021.

Corresponding author: Andrzej Borowski, Medical University of Lodz, Orthopedics and Pediatrics Orthopedics Department, Pomorska 251, 92-213 Łódź, Poland (e-mail: aborowski@xl.wp.pl). 
for extending the applicability of this surgical method. The research and observations made allow the continuous improvement of the currently used implants and the creation of new concepts of the structure, shape, alloy composition from which implants are made, as well as articulation methods and surgical techniques. All these efforts will likely result in the construction of an endoprosthesis with the longest possible biofunctionality in the patient's body $[1,2]$.

The objective of this work is to present the results of the analysis regarding the issue of return to professional activity by patients treated surgically with arthroplasty due to gonarthrosis among the Polish population.

\section{MATERIAL AND METHODS}

The clinic involved in this study currently performs $>300$ TKA procedures each year using several types of implants. In 2015-2016, a total of 459 TKA procedures were performed, based on which 88 working-age patients, i.e., women aged $\leq 59$ years and men aged $\leq 64$ years, were selected and further analyzed in this group. The study group ultimately consisted of 42 (42.1\%) women and 46 men. One female patient and 2 male patients were operated twice (Figure 1-3). The age was $\mathrm{M}=54.2$ years for women $(\mathrm{SD}=5.864, \mathrm{Me}=56)$, and $\mathrm{M}=58.1$ years for men $(\mathrm{SD}=5.346, \mathrm{Me}=59)$. The youngest woman to undergo the surgery was 37 years old, while the youngest man was 40 years old on the day of the surgery. The oldest woman to be operated on was 59 years old, while the oldest man was 64 years old on the day of the surgery. In the study group, the right knee joint was operated in $50(55 \%)$ cases, and the left knee joint was operated slightly less often, in 41 cases. In the examined female subgroup, the left knee joint was operated in $14(34.1 \%)$ cases, while the right knee was operated 29 times. In the examined male subgroup, the left knee joint was operated in $27(65.9 \%)$ cases, and the right knee was operated 21 times.
There were 42 intellectual workers and 46 physical workers in the study group. Most of the intellectual workers declared college education (76\%), and all of the physical workers declared vocational education.

All procedures were performed under epidural anesthesia, using the midvastus approach each time. The pneumatic tourniquet cuff was tightened only at the stage of implanting the endoprosthesis and the postoperative drain was left for $24 \mathrm{~h}$. In the group of patients being discussed, TKA was performed using only the cementing technique. The analysis of the types of implants used indicates that the most frequently implanted endoprostheses were Evolution Medial-Pivot (in 33 cases - 36.3\%), PFC (in 22 cases $-24.2 \%$ ), Vanguard (in 21 cases $-23 \%$ ) and Columbus (in 13 cases $-14.3 \%$ ). In one case of a significant knee joint instability due to insufficiency of the tibial collateral ligament, there was a need to use a partially bound RT-Plus endoprosthesis. All patients received standard antithrombotic and antibacterial prophylaxis. On the first day after the procedure, patient verticalization and rehabilitation were commenced using the continuous passive motion splint for passive exercises. Partial limb loading was allowed from the first day after the surgery, and total limb loading as soon as possible.

In most cases, i.e., $87.9 \%$ corresponding to 80 knee joints, the reason for performing arthroplasty was idiopathic gonarthrosis, and the remaining 11 procedures concerned posttraumatic, post-inflammatory and rheumatoid diseases.

The study had a retrospective character. All the patients participating in the study underwent a clinical and radiological assessment before the alloplasty procedure and, following a request letter or a telephone call, also during the last outpatient follow-up visit. At first after being discharged from the hospital, the patients were monitored 3, 6 and 12 months after the surgery. Later on, consecutive follow-up visits took place once a year.

A modified Knee Society Score (KSS) scale was used to develop the results of the clinical trial, which consists of 


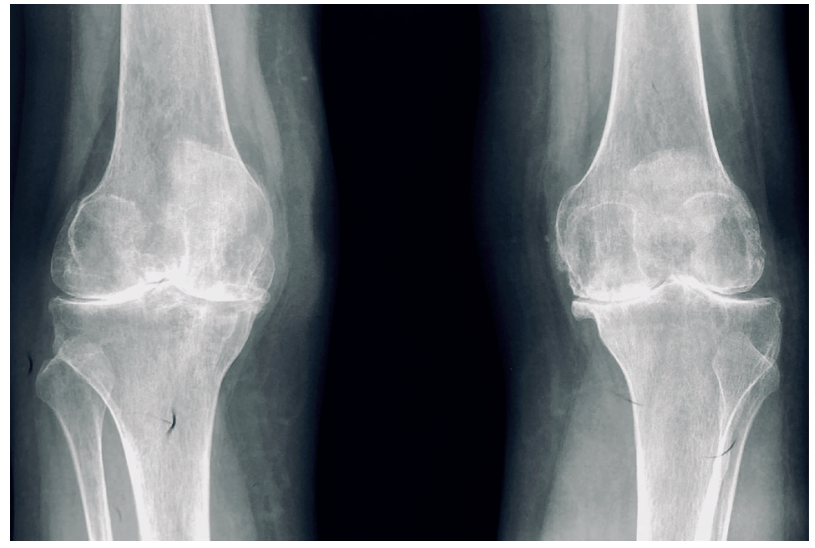

Figure 1. A 38-year-old female patient before admission to the Orthopedics Outpatient Clinic, Orthopedics and Pediatric Orthopedics Department, Łódź, Poland

an assessment of the knee function and an assessment of the patient's functions. The assessment of the knee function consists in assessing pain, the range of motion, stability and the occurrence of potential flexion contractures, extension losses or axial disorders. In this part of the classification, the patient can receive $0-100$ pts. The assessment of the patient's functions consists of assessing the walking distance, walking up the stairs and the use of orthopedic equipment. At this stage, the patient can also receive 0-100 pts [3]. Pain assessment was performed using a 10-point Visual Analogue Scale (VAS) [4].

The Kellgren-Lawrence classification was used to assess preoperative radiograms [5]. Radiographic studies were also an inseparable element of the follow-up examinations. In each case, a comparative X-ray of the knee joints was taken in the anterior-posterior (AP) and lateral standing projections. More specifically, X-ray images were made including the central ray passing through the center of the patella. The following parameters were evaluated: the position of the joint space, the location of the femoral and tibial components of the endoprosthesis, the possible appearance of clear zones around the endoprosthesis, any features of loosening, and signs of wear or damage to the implants. In order to accurately assess

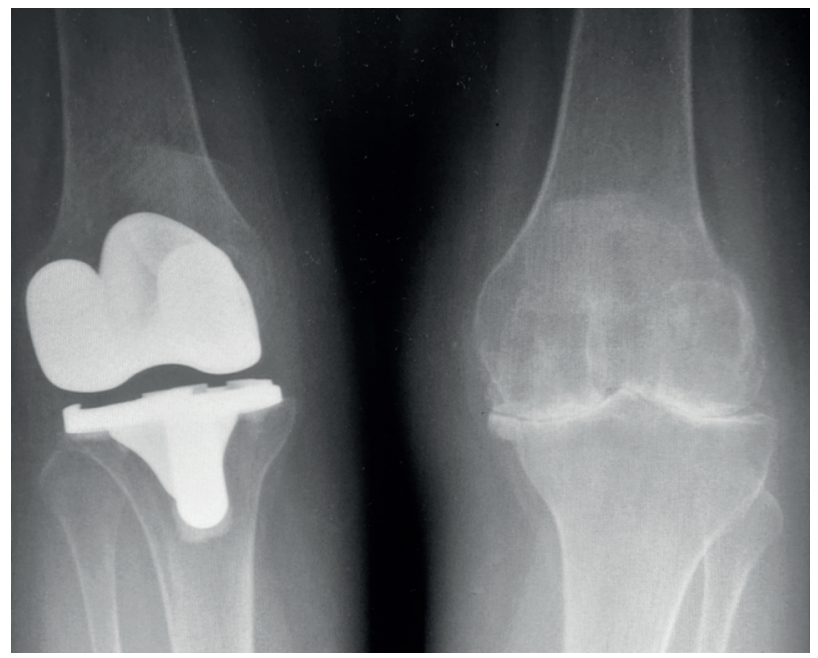

Figure 2. Condition after total right knee arthroplasty performed on November 2, 2015, in the Orthopedics Outpatient Clinic, Orthopedics and Pediatric Orthopedics Department, Łódź, Poland

the setting of the endoprosthetic components, the following angles were measured: the coronal-femoral component angle and the coronal-tibial component angle on X-ray images made in the AP projection, as well as the sagittal-femoral component angle and the sagittaltibial component angle on X-ray images made in the lateral projection. It is worth emphasizing that, in all cases, the radiographic evaluation was performed by an independent researcher not involved in performing the surgery under study [6].

All the procedures performed under this study design were conducted in compliance with the standards of the 2013 version of the Declaration of Helsinki. The study was approved by the Bioethics Committee of the Medical University of Łódź with reference number RNN/180/14/EC. The obtained results were subjected to the statistical analysis using the Statistica v. 10.0 PL program. Chi-squared test was used to calculate differences between the patients coming back to work and those who did not, and also the relationship of coming back to work between the physical and intellectual workers. To assess the significance of coming back to work among the patients who 


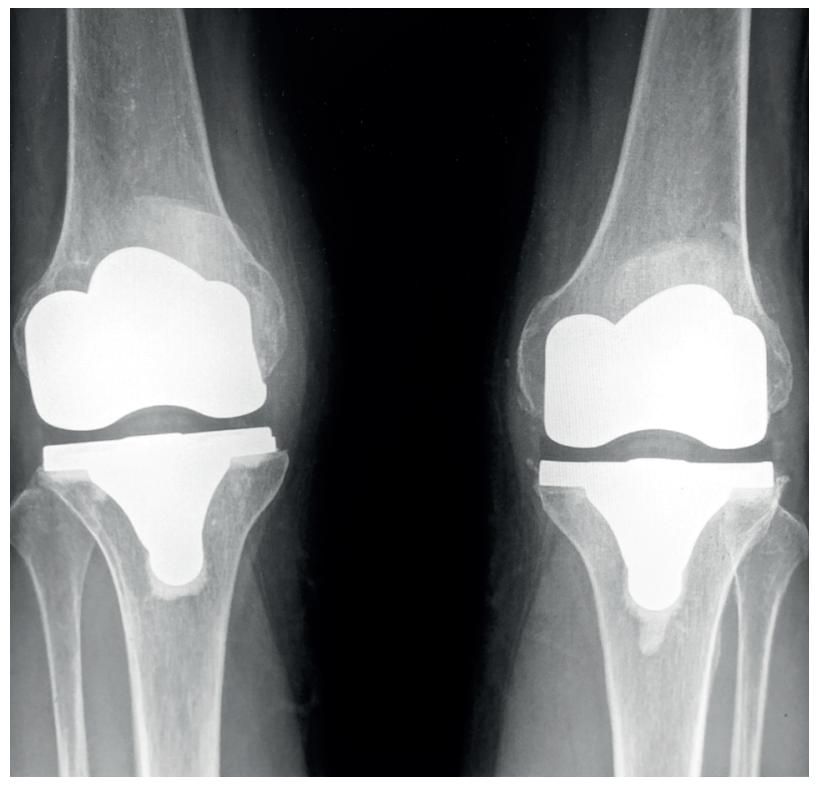

Figure 3. Condition after total left knee arthroplasty performed on July 7, 2016, in the Orthopedics Outpatient Clinic, Orthopedics and Pediatric Orthopedics Department, Łódź, Poland

were previously unemployed, Fisher's exact test was used. Levene's test was used to check the normality of distribution. Differences in the length of annual leave in relation to the severity of gonarthrosis was calculated using the Mann-Whitney U test.

The work was created with the proprietary resources of one of the authors; the research was not funded from any other source.

\section{RESULTS}

The average waiting period for the surgery was over 831.2 days $(\mathrm{SD}=533.54, \mathrm{Me}=672.5)$, ranging 78-2366 days in cases of postponing the date of the surgery at the patient's request. The mean length of the follow-up was determined at 1381.6 days $(\mathrm{SD}=187.281, \mathrm{Me}=1374$ ) (Table 1). The analysis of the patients' age led to the conclusion that the patients operated on account of posttraumatic gonarthrosis were younger $(\mathrm{M}=45.1$ years) than those operated for idiopathic degenerative disease
( $\mathrm{M}=54.2$ years). This dependency was statistically significant $(\mathrm{p}=0.001)$.

The average period of stay at the clinic was 8 days. The shortest hospitalization lasted 4 days, while the longest hospital stay was 15 days. The dependence of the duration of hospitalization on the etiology of a degenerative disease proved to be statistically significant. The shortest hospital stays were recorded in cases of idiopathic gonarthrosis, and the longest postoperative period was spent in the hospital by the patients operated on due to severe degenerative changes resulting from past intra- and periarticular fractures.

All patients qualified for the study group appeared for the control visit or provided replies regarding the issues under study by phone. According to the KSS clinical score, a very good result was recorded in 65 cases $(71.4 \%)$, a good result was obtained in 20 cases $(22 \%)$, and a satisfactory result was found only in 6 cases $(6.6 \%)$. The clinical and functional scores together with the range of motion are presented in Table 2. No fatal, septic, thromboembolic or aseptic loosening of the endoprosthesis was recorded.

In the adopted method of radiological assessment, considering the very short duration of the follow-up, no radiological symptoms of the aseptic loosening of the endoprosthesis were found, simultaneously confirming the correct embedding of the endoprosthesis components each time. Using VAS as another research tool, the authors received the following results as expected: before the surgery, the average score was $6.5 \mathrm{pts}$, while the average score after knee arthroplasty was 1.8 pts. The obtained improvement in these results is statistically significant $(p=0.0002)$.

Only $53(58.3 \%)$ of the examined patients were professionally active before undergoing surgical treatment and $46(50.5 \%)$ patients commenced work after the end of treatment $(p=0.29)$. However, a detailed analysis of this process showed that only in 3 cases $(7.9 \%)$ the previously unemployed patients took up a job and none of the pa- 
Table 1. Characteristics of the study group from the last follow-up visit in 2020 at the Orthopedics Outpatient Clinic, Orthopedics and Pediatric Orthopedics Department, Łódź, Poland

\begin{tabular}{|c|c|c|c|}
\hline \multirow{2}{*}{ Variable } & \multicolumn{3}{|c|}{$\begin{array}{l}\text { Participants } \\
(\mathrm{N}=88)\end{array}$} \\
\hline & $\begin{array}{c}\text { women } \\
(\mathrm{N}=42,47.7 \%)\end{array}$ & $\begin{array}{c}\text { men } \\
(\mathrm{N}=46,52.3 \%)\end{array}$ & total \\
\hline Surgery $[\mathrm{n}(\%)]$ & $43(47.3)$ & $48(52.7 .5)$ & 91 \\
\hline right knee & $29(58)$ & $21(42)$ & 50 \\
\hline left knee & $14(34.1)$ & $27(65.9)$ & 41 \\
\hline 2-stage left and right knee & $1(0.42)$ & $2(0.92)$ & 3 \\
\hline \multicolumn{4}{|l|}{ Age on the day of the surgery [years] } \\
\hline M & 54.2 & 58.1 & \\
\hline $\min .-\max$ & $37-59$ & $40-64$ & \\
\hline \multicolumn{4}{|l|}{ Observation period [days/years] } \\
\hline $\mathrm{M}$ & $1381.6 / 3.78$ & $1381.9 / 3.78$ & $1381.8 / 3.78$ \\
\hline $\min .-\max$ & $1106-1812 / 3.03-4.96$ & $1114-1789 / 3.05-4.90$ & $1106-1812 / 3.03-4.96$ \\
\hline \multicolumn{4}{|l|}{ Waiting for surgery time [days/years] } \\
\hline M & $770.1 / 2.10$ & $883.9 / 2.42$ & $831.2 / 2.27$ \\
\hline $\min .-\max$ & $78-2247 / 0.22-6.15$ & $121-2366 / 0.33-6.48$ & $78-2366 / 0.21-6.48$ \\
\hline \multicolumn{4}{|l|}{ Education $[\mathrm{n}(\%)]$} \\
\hline higher/college (intellectual workers) & $27(64.3)$ & $15(35.7)$ & 42 \\
\hline vocational (physical workers) & $19(41.3)$ & $27(58.6)$ & 46 \\
\hline
\end{tabular}

tients resigned from their professional activity because of TKA $(p=0.12)$. The lack of professional activity in the patients performing work before the surgical treatment was recorded 10 times $(11 \%)$; all those patients asked for the surgery before retirement and did not plan to come back to work after TKA.

Among the patients holding relevant qualifications, the average period of sick leave after the surgery was 136.2 days, and 9 patients were additionally treated on rehabilitation wards. As expected, most cases of the cessation of professional activities and the rehabilitation processes taking longer were recorded among the patients with severe post-traumatic gonarthrosis ( $\mathrm{M}=202.5$ days) than among the patients treated for idiopathic gonarthrosis $(M=121.3$ days $)(p=0.01)$.
Among the physical workers 23 out of 46 patients, and among the intellectual workers 31 out of 42 patients, came back to work. The physical workers were production and warehouse workers. None of the patients declared themselves as a farmer. On the other hand, 65\% of the intellectual workers were corporate lower-level workers, while the rest were freelance workers. Finally, $76 \%$ of the intellectual workers declared college education, while all of the physical workers declared vocational education.

The nature of the work performed proved to be statistically significant $(p=0.01)$ in favor of the intellectual workers who more often took up their previous jobs.

Many patients, for fear of losing their jobs or other negative consequences of being on a long sick leave, deliber- 
Table 2. Clinical data of 88 employed patients ( 91 knees) who had total knee replacement in 2020 at the Orthopedics Outpatient Clinic, Orthopedics and Pediatric Orthopedics Department, Łódź, Poland

\begin{tabular}{|c|c|c|c|c|}
\hline Parameter & Min.-max & M & $\mathrm{SD}$ & $\mathrm{p}$ \\
\hline Range of motion [degrees] & & & & 0.004 \\
\hline preoperative & $35-145$ & 96.7 & 30.1 & \\
\hline postoperative & $60-140$ & 110.1 & 17.6 & \\
\hline Flexion [degrees] & & & & 0.26 \\
\hline preoperative & $40-150$ & 106.5 & 28.3 & \\
\hline postoperative & $60-140$ & 111.3 & 17.4 & \\
\hline Extension [degrees] & & & & $<0.00001$ \\
\hline preoperative & $0-(-20)$ & -8.1 & 9.7 & \\
\hline postoperative & $0-(-5)$ & $-0,3$ & 1.2 & \\
\hline \multicolumn{5}{|l|}{ Knee Society Score [pts] } \\
\hline clinical & & & & $<0.0001$ \\
\hline preoperative & $20-72$ & 59 & & \\
\hline postoperative & $72-100$ & 88 & & \\
\hline functional & & & & $<0.0001$ \\
\hline preoperative & $40-81$ & 65 & & \\
\hline postoperative & $750-100$ & 90.5 & & \\
\hline
\end{tabular}

ately planned the surgical treatment for the final period of their professional activity.

\section{DISCUSSION}

Since the first implantation of a knee joint endoprosthesis by Glück in 1890, enormous progress has been made in this field of orthopedic surgery. By introducing new materials, technical solutions, modern articulations and surgical techniques, a modern knee joint endoprosthesis has been obtained. Currently, TKA is the method of choice in the treatment of extensive and advanced degenerative knee changes of various etiology.

Due to the relatively short duration of the follow-up, the results obtained by the authors in this clinical and radiological assessment should be approached with appropriate caution. Nevertheless, the subjective evaluation of patients after knee arthroplasty was significantly better than the final results obtained using the modified KSS classification. The greatest improvement was noted in the significant reduction or elimination of pain, as well as in the increase in the mobility range of the operated joint. The improvement of these parameters contributed to the improvement of the overall evaluation of the operated knee functions and the degree of patient satisfaction with the obtained result. As expected, relatively the worst final results were recorded in the group of patients operated on for post-traumatic gonarthrosis, which was caused by severe multi-organ and multi-site injuries within the locomotor system. In this form of gonarthrosis, one may encounter extremely severe deformations of the anatomical structure of the knee. This applies to both bony as well as ligamentous, capsular and muscle elements. The image of these deformations is often additionally complicated by the effects of previous surgical interventions. 
The results presented by the authors of this study correspond with other works dealing with this subject. In 2014, Tilbury et al. [7] conducted a multicenter study on the professional status of patients receiving treatment through surgical arthroplasty of the hip and knee joints. They analyzed the results of 19 studies published in 1986-2013; in total, 3872 patients who underwent arthroplasty were included in the study. The percentage of those returning to professional activity ranged 25-90\% during the follow-up period lasting 1-12 months, and the average time needed to return to work was determined to be 1.1-13.9 weeks [7].

A year later, Tilbury et al. [8] presented the results of a prospective study, the purpose of which was to determine the return to professional activity and the time off needed to return to work taken by the patients treated surgically with implanting a knee endoprosthesis. Eventually, 71 patients who had been professionally active before the surgery were qualified for the study group. One year after arthroplasty, 64 patients (90\%) returned to professional activity, 9 of whom (14\%) started to work shorter hours. The average time needed to return to work was 12.5 weeks.

Boeresma et al. [9] analyzed the results of 243 patients treated with TKA due to a degenerative disease. The mean age of the patients was 56 years, and the average time needed to return to work after the knee replacement surgery was 93 days. In the conclusions, the authors stated that the preoperative level of physical activity did not affect the time needed to take up professional activity after knee arthroplasty.

Nonetheless, Nouri et al. [10] examined 45 patients after knee arthroplasty in order to obtain information regarding the possibility of returning to work. The patients included in the study reported the shortage of information about the time needed to return to professional activity and the lack of an individual approach to this issue.

McGonagle et al. [11] analyzed the results of 58 patients aged $\leq 65$ years who underwent knee arthroplasty which was carried out in 2015-2017. Return to professional activity after approximately 7.7 weeks was recorded in $91 \%$ of these cases. The nature of the occupation performed did not affect the time needed to return to work. The aforementioned observations were confirmed by Maillette et al. [12] who examined 283 patients after the implantation of a knee joint endoprosthesis. They also found no dependency between the preoperative level of physical activity and the time needed to return to work.

Lankinen et al. [13] asked themselves a question: are there any patient-related variables that can affect the return to professional activity after knee arthroplasty? The study group was formed out of 151901 patients from the national register of Finnish endoprostheses, who were sent an appropriate questionnaire. The rate of received responses ranged $65-73 \%$. The conclusions stated that intellectual work, general well-being and remaining on a short sick leave before arthroplasty, lasting $<30$ days, are the variables related to the increased probability of returning to the occupation performed.

In another study, Hoorntje et al. [14] analyzed the results of TKA in 293 patients who were professionally active before the surgery. In the studied group of patients, the preoperative level of physical activity of the patients did not affect the time needed to return to professional activity after the surgical treatment. Only the level of patient expectations and adequate motivation proved to be significant with regard to the issue under study.

Van Zaanen et al. [15] conducted a multicentre study including a total of 292 patients who were professionally active before knee arthroplasty. The research tool used was the Work, Osteoarthritis or Joint-Replacement Questionnaire (WORQ) survey. In the conclusions, the authors stated that $30 \%$ of the patients did not expect any improvement or they even expected a deterioration of the ability to perform many activities requiring the smooth functioning of the operated knee joint [15]. 
In turn, Scott et al. [16] examined 289 patients aged $\leq 65$ years who underwent TKA. The applied research tools included WORQ, the Oxford Knee Score and the University of California Los Angeles surveys. Overall, $90 \%$ of the patients in the study group were professionally active before the surgery and $34 \%$ of them returned to their previous work upon the completion of treatment. The patients who did not work before the surgery usually did not take up work after endoprosthetic treatment. The high level of physical activity after the surgery did not affect the time needed to return to work. The patient's age turned out to be an important variable. All the operated patients aged $\leq 50$ returned to their professional activity. Only $60 \%$ of the operated patients aged 51-54 years returned to work, and nearly $24 \%$ of the patients aged 55-59 pursued professional activity after the surgical treatment.

In 2016, Leichtenberg et al. [17] examined the determinants of the lack of or only partial return to work by patients after knee arthroplasty. From the study group of 67 patients, 10 patients (19\%) returned to work on a part-time basis, and 6 patients (11\%) did not return to work during the observation period which lasted 1 year. The best results regarding the discussed issue were obtained in the group of patients running their own business characterized by a higher rate of professional activity.

In turn, Bardgett et al. [18] analyzed the factors reported by the patients and affecting their return to work after knee arthroplasty. The patients identified 3 main variables which influenced their return to professional activity. These were increased physical and mental work efficiency, compared to the preoperative state, a lack of professional help in returning to work, and assistance in the adaptation of the workplace.

Kleim et al. [19] continued the aforementioned considerations in their study. The study group consisted of 102 patients treated with knee arthroplasty, and 80 patients from this group returned to work 12 weeks after the surgery on average. In their conclusions, the authors emphasized a significantly longer period of return to professional activity for manual workers.

In another study, Sankar et al. [20] analyzed a group of 190 patients undergoing knee arthroplasty using the Workplace Activity Limitations Scale questionnaire. Within 1 year after the implantation of the endoprosthesis, $87 \%$ of the patients returned to work in their profession. Men with higher education, working in business, administration and finance, whose mode of work was characterized by low physical activity, returned to work the earliest.

On the other hand, Glebus et al. [21] examined a group of 42 young patients employed in uniformed services and subjected to arthroplasty of large joints. During an observation period of 2 years, $86 \%$ of the patients returned to professional activity. In this study, the Short Musculoskeletal Functional Assessment scale was used.

Lombardi et al. [22] analyzed the results of 661 TKA procedures with regard to resuming work. In this study group, during the observation period lasting 1-5 years and with the average age of the operated patients being 54 years, $75 \%$ of the patients had been professionally active within 3 months before the planned surgery, and $89 \%$ of them returned to work after the end of treatment and rehabilitation.

Clyde et al. [23] observed a group of 164 patients among whom a total of 177 arthroplasty procedures of big joints were performed in the period of 2000-2009. Following these, $70.2 \%$ of the patients receiving treatment returned to professional activity. The average time needed by the patients to return to work was 16.4 weeks.

Kievert et al. [24] formed a study group of 480 patients who underwent knee arthroplasty. According to the interview covering 2 years before the endoprosthetics, $173(36 \%)$ patients were professionally active, and 102 (58.9\%) returned to work within 6 months of the surgery.

Kuijer et al. [25] reviewed the literature regarding the issue of returning to work after hip and knee arthroplasty in the PubMed database. No difference was demonstrated in 
returning to work in terms of limiting mobility and loading the operated limb, and continuing further mobility improvement according to the pattern learned during the hospital stay. The authors pointed out the difficulties regarding the comparison of the analyzed studies in the aspect of the lack of relevant data and a uniform assessment system. In 2016, the same team of researchers focused on describing the characteristics of a group of patients who had unfavorable prognosis with regard to returning to professional activity after having a knee joint endoprosthesis implanted. They analyzed 764 patients who were assessed in terms of age, gender, comorbidities, the body mass index (BMI), preoperative sick leave duration, as well as complaints reported by the patient regarding the operated knee, resulting from the nature of the work performed and workplace requirements, and, finally, the Knee Injury and Osteoarthritis Outcome Score (KOOS) results. Remaining on a sick leave for $>2$ weeks before the surgery appeared to be closely related to the lack of return to professional activity after knee arthroplasty. Female sex, a BMI of $>30$, ailments arising from the nature of the work performed and workplace requirements proved less important. The patient's age and KOOS results were insignificant [26].

In turn, Foote et al. [27] examined the return to work of 109 patients aged $\leq 60$ years who were treated with an endoprosthesis for gonarthrosis. In the analyzed group, $82 \%$ of the patients were professionally active before the surgery, and $57(52.3 \%)$ returned to professional activity.

In another study, Boeresma et al. [9] analyzed the results of 243 surgeries in patients treated with TKA because of osteoarthritis. The mean age of the patients was determined to be 56 years, and the average time needed to return to work after knee replacement surgery was 93 days. In the conclusions, the authors stated that the preoperative level of physical activity does not affect the time needed to take up professional activity after knee arthroplasty.

On the other hand, Nouri et al. [10] examined 45 patients after knee arthroplasty in order to obtain information re- garding the possibility of returning to work. The patients included in the study reported the lack of information about the time needed to return to professional activity and the lack of an individual approach to this issue.

McGonagle et al. [11] analyzed the results of 58 patients aged $\leq 65$ years who underwent knee arthroplasty, which were performed in 2015-2017. The return to professional activity after an average of 7.7 weeks was recorded in $91 \%$ of these cases. The nature of the work performed did not affect the time needed to return to work.

The aforementioned observations were confirmed by Maillette et al. [12] who examined 283 patients after implantation of a knee joint endoprosthesis. They also found no relationship between the preoperative level of physical activity and the time needed to return to work.

The above considerations clearly confirm the effectiveness of knee arthroplasty and the beneficial impact of this procedure on the capability of returning to professional activity in the operated patients. The results in this scope differ significantly from the literature data. Many factors have contributed to this. A significant improvement in the quality of life after knee arthroplasty, including the improvement of the range of mobility, locomotion and reduction or even elimination of pain, provided excellent conditions for returning to work. The authors' observations have shown that the patients did not take up work for reasons related to the performed surgery. This condition was affected by their previous dissatisfaction with the professional work performed, low wages, excessively long periods of incapacity for work before the surgery and getting used to being out of work, and remaining on sickness allowance or benefit. In addition, the long waiting time for knee arthroplasty deteriorated the possibility of returning to work.

The long waiting time for the planned surgery has a substantially adverse effect on the patients' return to work. Insufficient financing of this type of medical procedures and limiting these services cause the waiting period for knee arthroplasty to exceed several years. The queue of patients 
awaiting the surgery is a specific situation which needs to be coped with under the operating principles stipulated in the contract with the National Health Fund. Mainly for financial reasons, as well as due to limited contracts and the capabilities of the surgery ward, the clinic staff are forced to limit the number of arthroplasties performed. Another reason for postponing the surgery is the patients' fear of losing their jobs. Therefore, it is difficult to compare the observations made by the authors with the literature data, as the waiting period in EU countries or in the USA is counted in weeks. A short hospital stay in such situations allows patients to return to work after a short period of disability following the surgery.

The authors' observations demonstrated that people running their own business, with academic education, including especially doctors and lawyers, as well as patients who did not have to experience considerable physical exertion at work, returned to their professional work sooner. Also farmers returned to work very quickly.

The analysis of the literature supplies 3 additional pieces of information. Firstly, on account of the difference between the procedures of hip and knee arthroplasty, the specificity of rehabilitation procedures and the different nature of indications for these procedures, the data obtained from such patients should not be combined into a common study group and further analyzed together. Secondly, it is very difficult to compare published research on a given hip or knee joint due to the large variety and discrepancy in the scales, classifications, questionnaires and other research tools applied. Thirdly, the etiology of osteoarthritis of the operated joint seems to be of key importance. The prognoses for idiopathic degenerative changes differ from those for secondary osteoarthritis which stems from a rheumatic disease, trauma, necrosis or inflammation. The above information is frequently missing in the previously cited publications.

These observations and current conversations with the patients clearly suggest that an increasing number of pa- tients want and expect a quick return to work after knee arthroplasty. A gradual reduction of the waiting time for the procedure itself, improvements in the surgical technique, rapid rehabilitation of patients, as well as the growing patient awareness contribute thereto.

\section{CONCLUSIONS}

In working-age patients, TKA is a valuable method of surgical treatment for advanced gonarthrosis of varying etiology. Most of the patients who worked before the surgery returned to work in the position held and on the same fulltime equivalent basis.

\section{REFERENCES}

1. Taunton MJ. What's New in Adult Reconstructive Knee Surgery. J Bone Joint Surg Am. 2019;101(2):103-11, https://doi. org/10.2106/JBJS.18.01157.

2. Taunton MJ. What's New in Adult Reconstructive Knee Surgery. J Bone Joint Surg Am. 2020;102(2):91-100, https://doi. org/10.2106/JBJS.19.01063.

3. Insall JN, Dorr LD, Scott RD, Scott WN. Rationale of the Knee Society clinical rating system. Clin Orthop Relat Res. 1989;(248):13-4.

4. Wewers ME, Rachfal C, Ahijevych K. A psychometric evaluation of a visual analogue scale of craving for cigarettes. West $\mathrm{J}$ Nurs Res. 1990;12(5):672-81, https://doi.org/10.1177/0193945 99001200508.

5. Kellgren JH, Lawrence JS. Radiological assessment of osteoarthrosis. Ann Rheum Dis. 1957;16(4):494-502, https://doi. org/10.1136/ard.16.4.494.

6. Ewald FC. The Knee Society total knee arthroplasty roentgenographic evaluation and scoring system. Clin Orthop Relat Res. 1989;(248):9-12.

7. Tilbury C, Schaasberg W, Plevier JW, Fiocco M, Nelissen RG, Vliet Vlieland TP. Return to work after total hip and knee arthroplasty: a systematic review. Rheumatology (Oxford). 2014;53(3):512-25, https://doi.org/10.1093/rheumatology/ ket389. 
8. Tilbury C, Leichtenberg CS, Tordoir RL, Holtslag MJ, Verdegaal SH, Kroon HM, et al. Return to work after total hip and knee arthroplasty: results from a clinical study. Rheumatol Int. 2015;35(12):2059-67, https://doi.org/10.1007/s00 296-015-3311-4.

9. Boersma AR, Brouwer S, Koolhaas W, Brouwer RW, Zijlstra WP, van Beveren J, et al. No association between preoperative physical activity level and time to return to work in patients after total hip or knee arthroplasty: A prospective cohort study. PLoS One. 2019;14(9):e0221932, https://doi.org/ 10.1371/journal.pone.0221932.

10. Nouri F, Coole C, Baker P, Drummond A. Return to work advice after total hip and knee replacement. Occup Med (Lond). 2020;70(2):113-8, https://doi.org/10.1093/occmed/kqaa014.

11. McGonagle L, Convery-Chan L, DeCruz P, Haebich S, Fick DP, Khan RJK. Factors influencing return to work after hip and knee arthroplasty. J Orthop Traumatol. 2019; 20(1):9, https://doi.org/10.1186/s10195-018-0515-x.

12. Maillette P, Coutu MF, Gaudreault N. Workers' perspectives on return to work after total knee arthroplasty. Ann Phys Rehabil Med. 2017;60(5):299-305, https://doi.org/10.1016/ j.rehab.2017.01.004.

13. Lankinen P, Laasik R, Kivimaki M, Aalto V, Saltychev M, Vahtera J, et al. Are patient-related pre-operative factors influencing return to work after total knee arthroplasty. Knee. 2019;26(4):853-60, https://doi.org/10.1016/j.knee.2019. 04.015 .

14. Hoorntje A, Leichtenberg CS, Koenraadt KLM, van Geenen RCI, Kerkhoffs G, Nelissen R, et al. Not Physical Activity, but Patient Beliefs and Expectations are Associated With Return to Work After Total Knee Arthroplasty. J Arthroplasty. 2018;33(4):1094-100, https://doi.org/10.1016/j.arth. 2017.11.032.

15. Van Zaanen Y, van Geenen RCI, Pahlplatz TMJ, Kievit AJ, Hoozemans MJM, Bakker EWP, et al. Three Out of Ten Working Patients Expect No Clinical Improvement of Their Ability to Perform Work-Related Knee-Demanding Activities After Total Knee Arthroplasty: A Multicenter Study.
J Occup Rehabil. 2019;29(3):585-94, https://doi.org/10.1007/ s10926-018-9823-5.

16. Scott CEH, Turnbull GS, MacDonald D, Breusch SJ. Activity levels and return to work following total knee arthroplasty in patients under 65 years of age. Bone Joint J. 2017;99B(8):1037-46, https://doi.org/10.1302/0301-620X.99B8.BJJ2016-1364.R1.

17. Leichtenberg CS, Tilbury C, Kuijer P, Verdegaal S, Wolterbeek R, Nelissen R, et al. Determinants of return to work 12 months after total hip and knee arthroplasty. Ann R Coll Surg Engl. 2016;98(6):387-95, https://doi.org/10.1308/rcsann. 2016.0158.

18. Bardgett M, Lally J, Malviya A, Kleim B, Deehan D. Patientreported factors influencing return to work after joint replacement. Occup Med (Lond). 2016;66(3):215-21, https:// doi.org/10.1093/occmed/kqv187.

19. Kleim BD, Malviya A, Rushton S, Bardgett M, Deehan DJ. Understanding the patient-reported factors determining time taken to return to work after hip and knee arthroplasty. Knee Surg Sports Traumatol Arthrosc. 2015;23(12):3646-52, https://doi.org/10.1007/s00167-014-3265-1.

20. Sankar A, Davis AM, Palaganas MP, Beaton DE, Badley EM, Gignac MA. Return to work and workplace activity limitations following total hip or knee replacement. Osteoarthritis Cartilage. 2013;21(10):1485-93, https://doi.org/10. 1016/j.joca.2013.06.005.

21. Glebus GP, Feather TW, Hsu JR, Gerlinger TL. Return to duty and deployment after major joint arthroplasty. J Arthroplasty. 2013;28(8):1270-3, https://doi.org/10.1016/j.arth. 2013.02.028.

22. Lombardi AV Jr., Nunley RM, Berend KR, Ruh EL, Clohisy JC, Hamilton WG, et al. Do patients return to work after total knee arthroplasty? Clin Orthop Relat Res. 2014;472(1):13846, https://doi.org/10.1007/s11999-013-3099-z.

23. Clyde CT, Goyal N, Matar WY, Witmer D, Restrepo C, Hozack WJ. Workers' Compensation patients after total joint arthroplasty: do they return to work? J Arthroplasty. 2013; 28(6):883-7, https://doi.org/10.1016/j.arth.2013.01.036. 
24. Kievit AJ, van Geenen RC, Kuijer PP, Pahlplatz TM, Blankevoort L, Schafroth MU. Total knee arthroplasty and the unforeseen impact on return to work: a cross-sectional multicenter survey. J Arthroplasty. 2014;29(6):1163-8, https://doi. org/10.1016/j.arth.2014.01.004.

25. Kuijer PP, Kievit AJ, Pahlplatz TM, Hooiveld T, Hoozemans MJ, Blankevoort L, et al. Which patients do not return to work after total knee arthroplasty? Rheumatol Int. 2016;36(9):1249-54, https://doi.org/10.1007/s00296-016-3512-5.
26. Kuijer PP, de Beer MJ, Houdijk JH, Frings-Dresen MH. Beneficial and limiting factors affecting return to work after total knee and hip arthroplasty: a systematic review. J Occup Rehabil. 2009;19(4):375-81, https://doi.org/10.1007/s10926009-9192-1.

27. Foote JA, Smith HK, Jonas SC, Greenwood R, Weale AE. Return to work following knee arthroplasty. Knee. 2010; 17(1):19-22, https://doi.org/10.1016/j.knee.2009.06.001.

This work is available in Open Access model and licensed under a Creative Commons Attribution-NonCommercial 3.0 Poland License - http://creativecommons.org/ licenses/by-nc/3.0/pl/deed.en. 